\title{
Relação entre cânone literário e ensino secundário no Brasil: das ditaduras ao estado democrático de direito
}

\author{
José William Craveiro Torres ${ }^{1}$
}

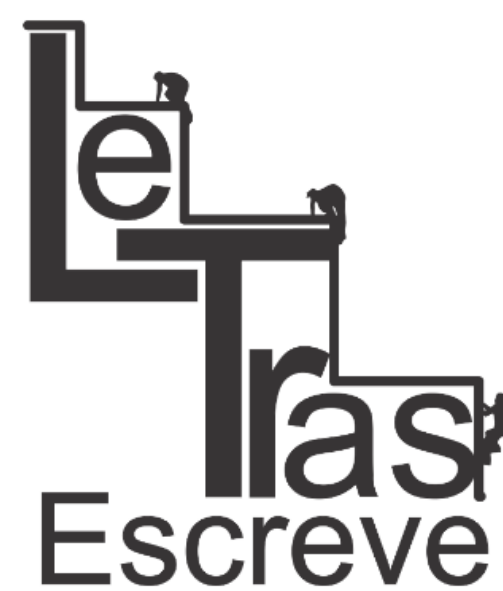

(ISSN 2238-8060)

Resumo: $O$ presente artigo aborda o cânone literário instituído pelos regimes ditatoriais brasileiros e verifica se o Brasil, depois de 1988, impôs ou sugeriu autores e obras às suas instituições de ensino. Iremos analisar leis e documentos oficiais que giram em torno do Ensino brasileiro, mas sempre enfocando o Ensino Médio para chegarmos à resposta que estamos buscando.

Palavras-chave: Cânone literário; Ditadura; Democracia; Brasil.

Abstract: This article discusses the literary canon established by Brazilian dictatorial regimes and checks if Brazil, after 1988, imposed or suggested authors and books to its educational institutions. We will analyze laws and official documents around Brazilian Education, but always focusing on high school to get the answer we are looking for.

Keywords: Literary Canon; Dictatorship; Democracy; Brazil.

\section{INTRODUÇÃO}

Ao longo do período republicano (1889-Atualidade), o Brasil enfrentou duas ditaduras: a da Era Vargas, conhecida por Estado Novo (1937-1945), e a Militar (1964-1985). Durante esses momentos, como costuma acontecer em regimes ditatoriais, tudo passou a ser controlado pelo Estado (instituições, Povo), como forma de garantir a "ordem" necessária para que os seus objetivos (o "Progresso"), de variegada natureza (políticos, econômicos, sociais), pudessem ser atingidos.

Um desses mecanismos de controle estatal recaiu, evidentemente, sobre a Educação: por meio dela, o Estado, tanto na Era Vargas quanto na época da Ditadura Militar, dizia o que os

\footnotetext{
${ }^{1}$ Doutorando em Literatura de Língua Portuguesa, Investigação e Ensino, pela Faculdade de Letras da Universidade de Coimbra - FLUC; bolsista de Doutorado Pleno no Exterior da Coordenação de Aperfeiçoamento de Pessoal de Nível Superior - CAPES (processo 0952/12-5). E-mail: williamcraveiro@hotmail.com
}

https://periodicos.unifap.br/index.php/letras

Macapá, v. 6, n. I, Io semestre, 2016. 


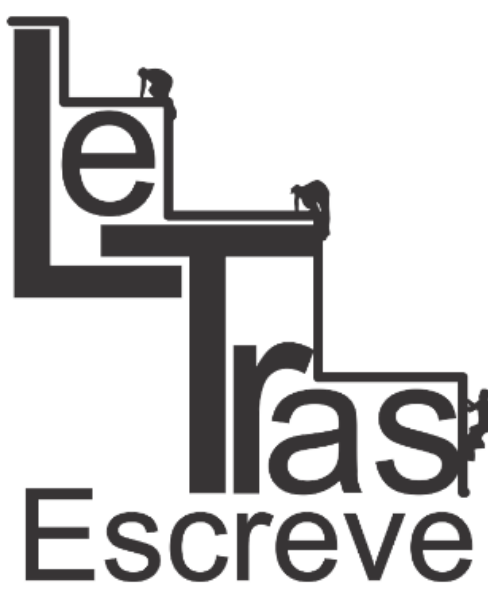

(ISSN 2238-8060) estudantes brasileiros deveriam ou não aprender, bem como a forma como essa aprendizagem deveria ocorrer; ou seja, conteúdos e metodologias eram repassados aos sistemas de ensino público e privado, às instituições educacionais, por meio de leis e de documentos específicos, cabendo aos professores colocar em prática aquilo que tinha sido estabelecido pela alta cúpula do Governo e assinado pelo ministro da Educação e pelo presidente da República. O Ensino, no Estado Novo e ao longo da Ditadura Militar, era marcadamente nacionalista e visava o controle social a partir do "amor à Pátria": os conteúdos ministrados aos estudantes geralmente giravam em torno do Brasil e de suas regiões, do povo brasileiro (ou dos "povos brasileiros") e, claro, das ações "progressistas" do Governo.

A Língua Portuguesa teve papel de destaque, nesses períodos, por ser a "Língua Mãe", o idioma oficial brasileiro. O seu ensino dava-se por meio da Gramática Normativa, que, por sua vez, ia buscar os exemplos de linguagem castiça nos grandes clássicos das Literaturas Portuguesa e Brasileira: Os Lusíadas e romances de José de Alencar e de Machado de Assis certamente figuravam entre essas obras. O Ensino das Línguas Estrangeiras (Inglês, Francês e Alemão, principalmente), nas escolas, também estava atrelado, direta ou indiretamente, a clássicos da Literatura Universal.

A Literatura, no entanto, não serviu apenas para exemplificar o bom uso das Línguas, nos momentos de Ditadura: clássicos da Literatura Universal, da Portuguesa e da Brasileira fizeram parte da lista de livros que os estudantes, sobretudo os secundaristas, deveriam ler ao longo de sua escolarização. Havia, assim, um cânone literário estabelecido pelos governos ditatoriais. Tal lista de obras geralmente vinha acompanhada de uma série de justificativas que procuravam explicar por quais motivos eram essas, e não outras, aquelas que tinham sido escolhidas pelo Estado para a formação do povo brasileiro.

https://periodicos.unifap.br/index.php/letras Macapá, v. 6, n. I, Io semestre, 2016. 


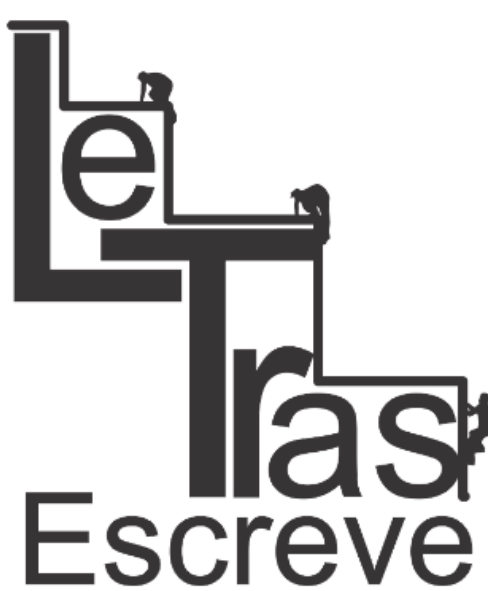

(ISSN 2238-8060)

Este artigo, como se pôde notar pelo seu título, tem por intuito tratar do cânone literário instituído pelos regimes ditatoriais supramencionados e verificar se, da forma como ocorreu nos momentos de Ditadura, o Estado brasileiro, após 1988, quando se autodenominou um "Estado democrático de direito" (BRASIL, 2012), impôs ou sugeriu, por meio de leis e/ou de documentos específicos, com intenções ideológicas e/ou pedagógicas, algum tipo de cânone literário às suas instituições de ensino, públicas e privadas. Também não iremos nos debruçar sobre todo o sistema de Ensino brasileiro (Fundamental, Médio e Superior) para chegarmos à resposta que estamos buscando, mas somente sobre o Ensino secundário ou Ensino Médio, por ser nesta etapa da escolarização em que o ensino de Literatura dá-se de forma universal, mais sistemática e mais intensa; inclusive por se tratar de uma disciplina com "vida própria" na grade curricular secundarista brasileira, estando, portanto, separada da de Língua Portuguesa.

No primeiro tópico desta investigação, baseados nas pesquisas do Prof. Doutor Luiz Eduardo Oliveira (2008), da Universidade Federal de Sergipe - UFS -, de seu orientando de iniciação científica, João Escobar José Cardoso (2010), e das investigações do Prof. Doutor Flávio René Kothe (2001), da Universidade de Brasília - UNB -, diremos como o Estado Novo e a Ditadura Militar lidaram com a questão da Literatura no sistema de Ensino secundário brasileiro: trataremos das regras estabelecidas pelo Regime ditatorial para a formação do cânone literário escolar e apresentaremos as obras que poderiam (ou que deveriam) ser lidas pelos estudantes secundaristas dos sistemas de ensino público e privado.

No segundo, analisaremos leis e documentos normativos do Estado brasileiro democrático (de 1988 aos nossos dias) para sabermos se, oficialmente, houve, em algum momento, de forma direta ou indireta, clara ou por meio das entrelinhas, uma tentativa de estabelecimento de um cânone literário brasileiro por parte do 


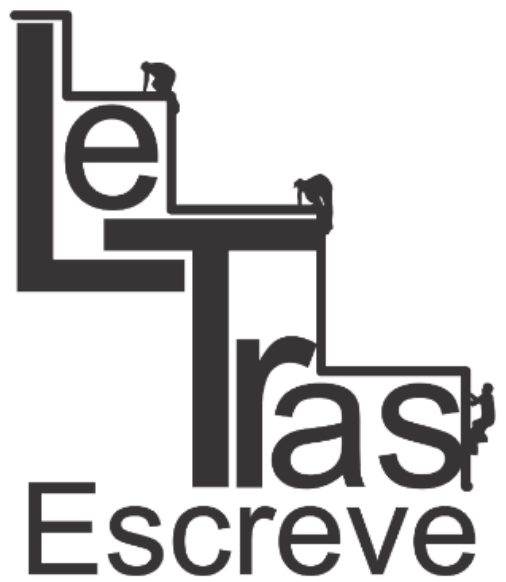

(ISSN 2238-8060)
Governo Federal. As leis e os documentos oficiais serão analisados a partir de um critério cronológico: começaremos pelo terceiro capítulo do Título VIII da Constituição de 1988 (BRASIL, 2012), intitulado "Da Educação, da Cultura e do Desporto"; passaremos pela Lei de Diretrizes e Bases da Educação Nacional, LDB 9.394/96 (BRASIL, 2010); pelas Matrizes Curriculares de Referência para o SAEB/97 (BRASIL, 1997); pelos Parâmetros Curriculares Nacionais: Ensino Médio (BRASIL, 2000); e pelos PCN+ Ensino Médio (Orientações Educacionais Complementares aos Parâmetros Curriculares Nacionais): Linguagens, Códigos e suas Tecnologias (BRASIL, 2002); até chegarmos às Orientações Curriculares para o Ensino Médio: Linguagens, Códigos e suas Tecnologias (BRASIL, 2006).

Ao cabo terá sido possível, acreditamos, chegar a uma conclusão quanto às leis e aos documentos oficiais analisados e dar uma resposta aos leitores quanto ao problema que nos motivou a escrever este artigo: saber se foi ou não estabelecido um cânone literário oficial por parte do Estado brasileiro a partir de 1988.

\section{Cânones literários em tempos de ditadura}

Conforme dissemos na Introdução, iremos tratar, neste tópico, da forma como o Estado Novo, ou Ditadura Vargas, e a Ditadura Militar de 1964 lidaram com a questão do Ensino de Literatura nas escolas de Ensino secundário (chamado de Ensino Médio, pela legislação brasileira em vigor) das redes pública e privada. Para tanto, debruçar-nos-emos, como foi dito, sobre as pesquisas realizadas pelo Prof. Doutor Luiz Eduardo Oliveira e por seu orientando de iniciação científica, João Escobar José Cardoso, no âmbito da Universidade Federal de Sergipe - UFS: ambos dedicaram-se à investigação do estabelecimento de um cânone literário para o Ensino da Literatura na época do Estado Novo ou da Ditadura Vargas. Quanto à relação entre Cânone e Ensino no

https://periodicos.unifap.br/index.php/letras Macapá, v. 6, n. I, Io semestre, 2016. 


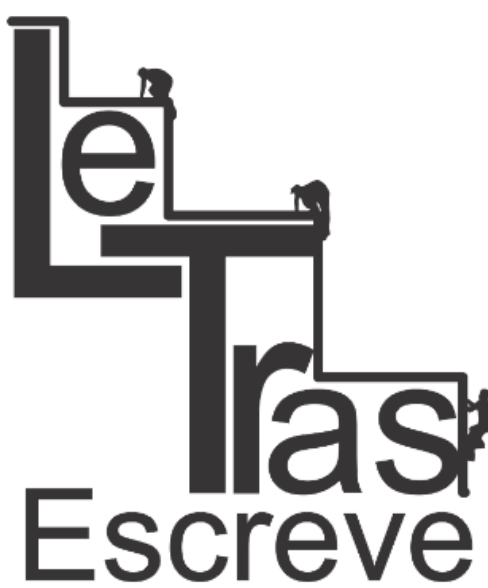

(ISSN 2238-8060) período da Ditadura Militar, reportar-nos-emos, ainda que de forma indireta (via notícia publicada no Jornal Estadão, do Estado de São Paulo, publicada em 03 de fevereiro de 2001, sem assinatura), ao estudo realizado sobre essa questão pelo Prof. Doutor Flávio René Kothe, da Universidade de Brasília - UNB.

A Era Vargas, como se sabe, durou quinze anos: teve início a partir de uma revolução em 1930, que pôs abaixo a República Velha, comandada pelos cafeicultores paulistas e pelos grandes pecuaristas mineiros, e terminou com a retirada de Getúlio do poder, em 1945. De 1930 a 1934, período do Governo Provisório de Vargas, pois não havia sido criada ainda uma nova Constituição para o país, o Brasil passou a ser governado por decretos-lei. Um desses decretos criou o Ministério da Educação e Saúde Pública, que foi entregue, nesse primeiro momento, a Francisco Campos. Este, com vista à criação de uma política nacional de Educação, a partir da qual os estados ficariam inteirados sobre os desejos e as necessidades do poder central, criou o Conselho Nacional de Educação, que existe até hoje e que está diretamente ligado ao Ministério da Educação - MEC. Desde o princípio já se pôde perceber, portanto, a preocupação do Governo Provisório getulista em centralizar o poder para garantir a ordem.

As primeiras medidas de Francisco Campos giraram em torno do Ensino da Língua Portuguesa e das Línguas Estrangeiras modernas. A Língua Portuguesa, como não poderia deixar de ser, foi vista como uma instituição nacional, como algo capaz de reforçar a identidade brasileira, de diferenciar o Brasil perante os demais países, inclusive com relação a Portugal. Acontece que, embora a ortografia oficial portuguesa tivesse sido adotada no Brasil desde o Governo Provisório de Vargas, o Estado resolveu adaptá-la à realidade linguística brasileira. Atrelado ao Ensino de Língua Portuguesa estava o Ensino de Literatura, que, de acordo com o Prof. Doutor Luiz Eduardo Oliveira, "deveria revelar as funções sociais e morais (...) da literatura" (OLIVEIRA, 2008, p. 03).

https://periodicos.unifap.br/index.php/letras Macapá, v. 6, n. I, Io semestre, 2016. 


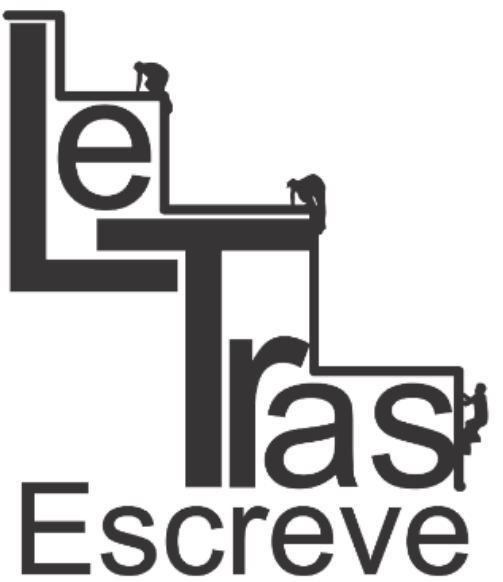

(ISSN 2238-8060)
O Ensino de Línguas Estrangeiras (notadamente do Inglês, do Francês e do Alemão) passou a ser realizado por meio da ligação direta da palavra ou da expressão estrangeira ao objeto referido, e não mais a partir da tradução de vocábulos ou de frases para o Português. Obras literárias em Língua Estrangeira também passaram a auxiliar os professores no ensino dos idiomas. Este foi um momento importante para o estabelecimento de um cânone (universal, ainda não nacional) por parte do Governo Provisório varguista. De acordo com o Prof. Doutor Luiz Eduardo Oliveira, o Decreto $\mathrm{n}^{\circ}$ 20.833, de 21 de dezembro de 1931, "indicava também os autores e obras cujos trechos, escolhidos pelo professor, deveriam ser lidos e interpretados na última série de cada língua estrangeira" (OLIVEIRA, 2008, p. 03).

Foi com Gustavo Capanema (ministro da Educação e da Saúde Pública de 1934 a 1945), no entanto, que o Ensino de Literatura Brasileira, no nível secundário, passou a ser melhor definido, sistematizado: conteúdos, objetivos e metodologia de ensino foram fixados pelo Governo por meio de uma portaria datada de 17 de março de 1936. De acordo com esse documento, os objetivos do Ensino de Literatura nas escolas secundaristas deveriam ser estes:

1 - dar conhecimento aos alunos do que há sido a atividade humana no imenso campo do pensamento, manifestada pelas obras literárias de toda natureza;

2 - preparar e educar o espírito dos alunos para a apreciação inteligente e crítica dos fatos literários;

3 - elevar o nível de cultura literária que o aluno deve trazer do curso fundamental, despertando-lhe o gosto pela boa leitura e estimulando os pendores aproveitáveis que nele porventura se revelem;

4 - auxiliar, na medida que as circunstâncias permitirem, o ensino das outras matérias, especialmente no tocante às línguas e às ciências sociais (BICUDO apud OLIVEIRA, 2008, p. 04).

Como disse o Doutor Luiz Eduardo Oliveira, em seu ensaio, "Como se pode notar, tratava-se de promover, entre o povo, uma

https://periodicos.unifap.br/index.php/letras

Macapá, v. 6, n. I, Io semestre, 2016. 


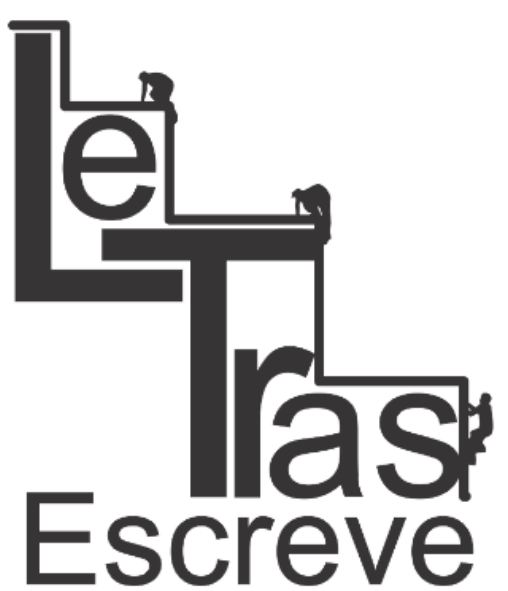

(ISSN 2238-8060) total nacionalização da cultura literária, de consolidar o cânone da literatura nacional" (OLIVEIRA, 2008, p. 04). Isso é tão verdade que o ministro Capanema, por meio da mesma portaria, instituiu que cada escola deveria ter uma biblioteca com uma seção exclusivamente dedicada à Literatura e que, nesta seção, só poderiam constar os livros autorizados pelo Governo. Sobre essa questão não podemos esquecer do papel que coube, à época, ao Instituto Nacional do Livro - INL -, responsável por muitas publicações (literárias, sobretudo) que foram, então, distribuídas às escolas públicas.

Essa preocupação de Gustavo Capanema com as obras literárias e com o material didático (que trazia textos literários) que poderiam entrar nas escolas culminou com a criação da Comissão Nacional do Livro Didático, por meio do Decreto $n^{\circ} 1.006$, de 30 de dezembro de 1938. Tal Comissão ficou encarregada de "examinar, julgar e autorizar o uso de todos os livros didáticos do ensino primário e secundário" (OLIVEIRA, 2008, p. 04). De acordo com o Artigo 20 do decreto há pouco mencionado,

Art. 20 - Não poderá ser autorizado o uso do livro didático:

a) que atente, de qualquer forma, contra a unidade, a independência ou a honra nacional;

b) que contenha, de modo explícito ou implícito, pregação ideológica ou indicação da violência contra o regime político adotado pela Nação;

c) que envolva qualquer ofensa ao chefe da Nação, ou às autoridades constituídas, ao Exército, à Marinha, ou às demais instituições nacionais;

d) que despreze ou escureça as tradições nacionais, ou tente deslustrar as figuras dos que se bateram ou se sacrificaram pela pátria, e que encerre qualquer afirmação ou sugestão, que induza o pessimismo quanto ao poder e ao destino da raça brasileira;

e) que inspire sentimento da superioridade ou inferioridade do homem de uma região do país, com relação ao das demais regiões;

f) que incite ódio contra as raças e as nações estrangeiras;

g) que desperte ou alimente a oposição e a luta entre as classes sociais;

h) que procure negar ou destruir o sentimento religioso, ou envolva o combate a qualquer confissão religiosa; 
i) que atente contra a família, ou pregue, ou insinue contra a indissociabilidade dos vínculos conjugais;

j) que inspire o desamor à virtude, induza o sentimento da inutilidade ou desnecessidade do esforço intelectual, ou combata as legítimas prerrogativas da personalidade humana (BICUDO apud OLIVEIRA, 2008, p. 05).

Como se pôde notar, o livro didático (ou a obra literária) deveria estar completamente aliançado com um dos princípios ideológicos do Estado Novo: proteção de Deus (da Igreja, da Religião; sobretudo da Católica), da Pátria e da Família. O cânone literário do Estado Novo então ficou assim estabelecido:

Para o estudo de literatura e dos gêneros literários, foram indicadas antologias francesas e inglesas, clássicos gregos (tradução), A Divina Comédia (tradução), Canção de Rolando (comentada), os teatros de Shakespeare, dos franceses, dos espanhóis e os de Ibsen (tradução), romances de Dostoiewsky, Gogol, Turfueneiff, Walter Scott, Dickens e o Fausto de Goethe (tradução), poesia, romance e teatro de Victor Hugo e $D$. Quixote de Cervantes. Para literatura portuguesa, Os Lusíadas (comentado), obras de Garrett, Castilho, Herculano, Eça de Queirós, contos de Fialho de Almeida, Poesias de Augusto Gil e Eugénio de Castro. Para literatura brasileira, antologias de autores brasileiros, cartas jesuíticas, obras completas de Cláudio Manuel da Costa, Alvarenga Peixoto, Silva Alvarenga e Álvares de Azevedo, Confederação dos Tamoios, Marilia de Dirceu, poesias de Fagundes Varela e Gonçalves Dias, romances de José de Alencar, Manoel de Macedo, Bernardo Guimarães e Alfredo Taunay, Memórias de um Sargento de Milícias, poesias e romances de Machado de Assis e o Ateneu de Raul Pompéia (BICUDO apud CARDOSO; OLIVEIRA, 2010, p. 04).

No que diz respeito ao cânone literário estabelecido pela Ditadura Militar, podemos afirmar que houve um retrocesso, quando o comparamos àquele imposto pela ditadura varguista: tanto no sistema de ensino público quanto no privado, os escritores estrangeiros, certamente pelo excesso de nacionalismo da época, foram dele retirados, motivo pelo qual prevalece, ainda hoje, nas escolas, apenas o ensino das Literaturas de Língua Portuguesa; notadamente o das Literaturas Brasileira e Portuguesa. Para o Prof. Doutor Flávio René Kothe, tal fato representa, hodiernamente, "um

https://periodicos.unifap.br/index.php/letras

Macapá, v. 6, n. I, Io semestre, 2016. 


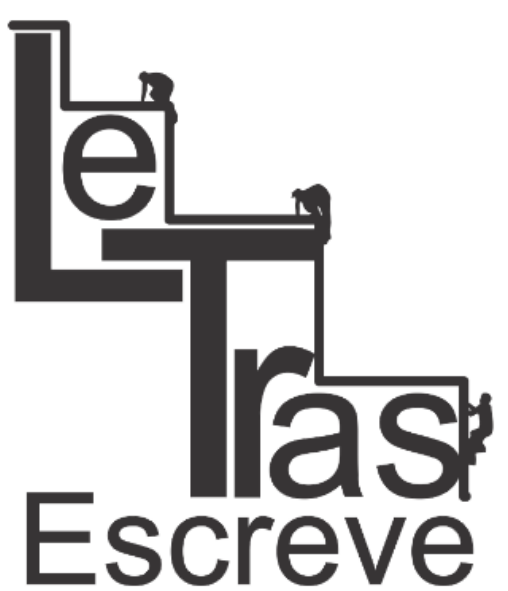

(ISSN 2238-8060)

tiro no pé, um fechamento inadequado a um período de globalização, em que o mercado pede mão-de-obra criativa" (CRÍTICO, 2001). Como saída para esse problema, ele sugere a combinação de leituras de obras da Literatura Universal com leituras de livros literários brasileiros, sem que haja uma supervalorização destes perante aquelas. A "xenofobia" literária era/é tal, para o Doutor Flávio René Kothe, que ele chega a afirmar que mesmo as obras literárias produzidas por imigrantes, no Brasil, não encontravam/encontram espaço no universo escolar. O mesmo acontecia/acontece a obras de outros autores, por não reforçarem a ideologia dominante. Exatamente por isso, Kothe afirmou para o Estadão.com.br que a Literatura Brasileira "não é uma expressão de todos os brasileiros" (CRÍTICO, 2001).

Este tópico teve o intuito de mostrar o quanto os cânones literários, nos tempos de Ditadura, estiveram relacionados à ideologia dominante: nacionalista, (ultra)direitista, conservadora e católica. Mais que a expressão de uma brasilidade, de um nacionalismo "sadio" ou do conhecimento de outras realidades, de outras culturas, o cânon literário, nos regimes ditatoriais, teve um fim claramente pedagógico, no sentido de que o Estado Novo e a Ditadura Militar utilizaram-no para incutir nos estudantes, sobretudo nos secundaristas, as suas ideologias, os seus valores. No próximo tópico, último deste artigo, verificaremos se houve estabelecimento de cânones literários - e, portanto, de ideologias por trás desses cânones - nas leis e nos documentos oficiais publicados a partir de 1988, quando o Brasil autodenominou-se um "Estado democrático de direito".

\section{Há um cânone literário oficial no Brasil, hoje?}

O terceiro capítulo do Título VIII da Constituição de 1988 trata da "Educação, da Cultura e do Desporto". Na primeira seção do referido capítulo, dedicada à Educação, não há nada relacionado ao 


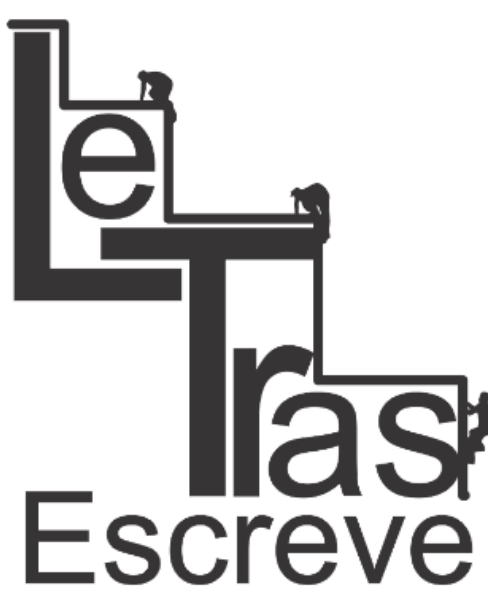

(ISSN 2238-8060)
Ensino de Literatura nas escolas. No entanto, a Carta Magna aponta a Língua Portuguesa como a oficial, de modo que todo o Ensino Fundamental deverá ser ministrado nessa língua. As comunidades indígenas poderão também utilizar as suas línguas para educar os seus, mas deverão também ministrar aulas para os estudantes em Português. Ainda de acordo com a Constituição, deverão ser fixados conteúdos mínimos para o Ensino Fundamental. No mais, essa primeira seção trata das garantias de uma Educação gratuita e de qualidade para todos os brasileiros, da liberdade e do pluralismo de ideias, da valorização dos profissionais da Educação, da autonomia das Universidades, dos programas suplementares capazes de garantir a permanência dos estudantes nas instituições de ensino (transporte, alimentação), da possibilidade de a iniciativa privada fazer parte do sistema de ensino e dos recursos que deverão ser dedicados à Educação.

A segunda seção do terceiro capítulo do Título VIII gira em torno da Cultura, mas também não trata da Literatura. A seção em apreço garante aos brasileiros o pleno exercício dos direitos culturais e o acesso à Cultura, a proteção das manifestações culturais populares, indígenas e afrobrasileiras, a proteção dos bens culturais materiais e imateriais, e trata dos tombamentos de documentos e de edifícios históricos, bem como dos recursos financeiros que deverão ser dedicados à Cultura.

A Lei de Diretrizes e Bases da Educação Nacional, LDB 9.394/96, trata de todo o sistema de ensino brasileiro: da Educação, dos Princípios e Fins da Educação Nacional, do Direito à Educação e do Dever de Educar, da Organização da Educação Nacional, dos Níveis e das Modalidades de Educação e Ensino, da Composição dos Níveis Escolares, da Educação Básica, da Educação Infantil, do Ensino Fundamental, do Ensino Médio, da Educação Profissional Técnica de Ensino Médio, da Educação de Jovens e Adultos, da Educação Profissional e Tecnológica, da Educação Superior, da Educação Especial, dos Profissionais da Educação, e dos Recursos

https://periodicos.unifap.br/index.php/letras Macapá, v. 6, n. I, Io semestre, 2016. 


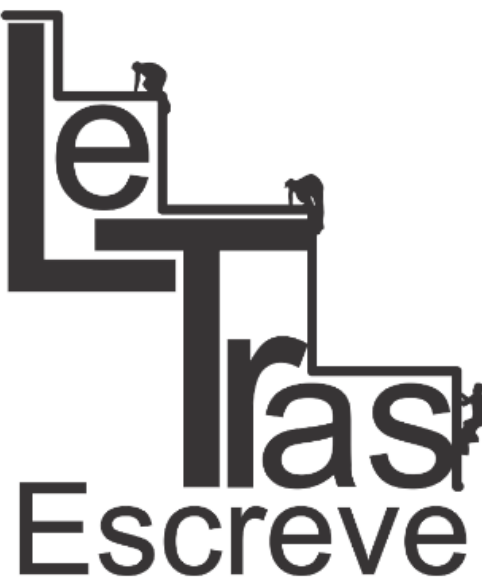

(ISSN 2238-8060)
Financeiros. No entanto, em nenhuma das páginas há qualquer alusão ao Ensino de Literatura e ao estabelecimento de cânones literários oficiais. Muito pelo contrário: a LDB, assim como a primeira seção do terceiro capítulo do Título VIII da Constituição de 88, abrese à pluralidade de ideias e de conteúdos: é o que defende o Art. 26 da Lei 9.394/96.

Como se pôde ver, mais uma vez o Governo Federal aponta o Ensino da Língua Portuguesa como obrigatório. No mais, a LDB permite que os conteúdos sejam adaptados à realidade de cada comunidade, de cada grupo social, desde que sejam garantidos a essa comunidade ou a esse grupo os conhecimentos (os conteúdos) indispensáveis a uma boa formação educacional.

As Matrizes Curriculares de Referência para o SAEB/97 tratam, sim, de Literatura, mas não do estabelecimento de cânones literários para os Ensinos Fundamental e Médio. Na verdade, o documento em questão aponta para os professores de Ensinos primário e secundário as competências que os alunos devem ou deveriam ter, em determinadas séries, ao ler textos de diversos gêneros.

Com relação ao Ensino de Literatura, os PCNs propõem menos História da Literatura e mais Leitura; inclusive em voz alta. As mesmas competências que os alunos devem desenvolver ou exercitar nas aulas de Língua Portuguesa (escrita, leitura, oralidade e audição) devem ser exercitadas ou desenvolvidas nas de Literatura. Os PCNs, assim como as leis e o documento oficial anteriormente citado (Matrizes Curriculares de Referência para o $S A E B / 97)$, também não estabelecem um cânone literário para o Ensino Médio; no entanto, levam aos professores alguns questionamentos que podem fazê-los pensar acerca do cânon escolar: "Machado de Assis é literatura? Paulo Coelho não? Por quê?" (BRASIL, 2000, p. 16).

Como podemos perceber pelo próprio título, os $\mathrm{PCN}+$ acrescentam algumas sugestões de trabalho àquelas que foram

https://periodicos.unifap.br/index.php/letras Macapá, v. 6, n. I, Io semestre, 2016. 
dadas aos professores pelos Parâmetros Curriculares Nacionais Ensino Médio, bem como reforçam outras: desenvolvem melhor, sobretudo, alguns comentários que foram feitos sobre o Ensino de Literatura nas escolas; todavia, como as leis e os documentos anteriormente citados, não apresentam aos professores nenhuma sugestão de cânone literário para o Ensino secundário.

A Literatura ganhou ainda mais espaço nas Orientações Curriculares para o Ensino Médio, de modo que os questionamentos levantados (mais do que as respostas dadas) são muitos; entretanto, nada de estabelecimento de cânone literário.

\section{CONSIDERAÇÕES FINAIS}

Ao cabo de tudo o que foi dito ao longo deste ensaio, chegamos a várias conclusões: (i) tratar de cânone literário é algo bastante complexo, porque obrigatoriamente temos de entrar noutras searas: Sociologia (noção de "Ideologia"), Antropologia ("o que é capaz de exprimir um povo?"), Ciências Políticas ("Colonialismo", "Nacionalismo"), História da Literatura, Ensino de

Literatura etc.; (ii) são muitos os critérios para o estabelecimento de um cânone: tudo vai depender das convicções e da formação de cada um que se lança sobre essa empreitada; (iii) não há estabelecimento de cânone sem a defesa de uma ideologia, de modo que resta saber sempre qual foi, é ou será a ideologia utilizada para a formação do cânon; (iv) os cânones literários estabelecidos no Estado Novo e na Ditadura Militar, como não poderia deixar de ser, estiveram a serviço do Estado, transmitindo e/ou reforçando as convicções e os valores (ultra)direitistas e conservadores dos governantes.

Após analisarmos leis e documentos específicos do Ministério da Educação, de 1988 a 2006, podemos afirmar, com certeza, que o Governo Federal já não mais interfere no sistema escolar, nesse sentido: ele deixa a escolha do cânone a cargo de cada uma das 
escolas secundaristas brasileiras, que deve discutir os livros a serem adotados ao longo do Ensino Médio com os professores da disciplina de Literatura no momento da preparação do Projeto Político-Pedagógico da instituição (o PPP).

\section{REFERÊNCIAS BIBLIOGRÁFICAS}

BICUDO, Joaquim de Campos. O Ensino Secundário no Brasil e sua Legislação Atual. São Paulo: AIFES (Associação de Inspetores Federais de Ensino Secundário), 1942.

BRASIL. Constituição da República Federativa do Brasil: texto constitucional promulgado em 5 de outubro de 1988, com as alterações adotadas pelas Emendas Constitucionais nos 1/1992 a 68/2011, pelo Decreto Legislativo $n^{\circ} 186 / 2008$ e pelas Emendas Constitucionais de Revisão nos 1 a 6/1994. 35. ed. Brasília: Câmara dos Deputados, Edições Câmara, 2012.

. LDB: Lei de Diretrizes e Bases da Educação Nacional: lei $n^{\circ}$ 9.394, de 20 de dezembro de 1996, que estabelece as diretrizes e bases da educação nacional. 5. ed. Brasília: Câmara dos Deputados, Coordenação Edições Câmara, 2010.

BRASIL. Ministério da Educação e do Desporto (1997). Instituto Nacional de Estudos e Pesquisas Educacionais. Matrizes Curriculares de Referência para o SAEB / Maria Inês Gomes de Sá Pestana et al. Brasília: INEP.

BRASIL. Ministério da Educação. Secretaria da Educação Básica (2006). Orientações Curriculares para o Ensino Médio: Linguagens, Códigos e suas Tecnologias. Brasília: MEC/SEB. (Vol. I).

BRASIL. Ministério da Educação e do Desporto. Secretaria de Educação Média e Tecnológica (2000). Parâmetros Curriculares Nacionais: Ensino Médio. Brasília: SEMTEC. (2002). PCN+ Ensino Médio (Orientações Educacionais

Complementares aos Parâmetros Curriculares Nacionais): Linguagens, Códigos e suas Tecnologias. Brasília: SEMTEC. 
CARDOSO, João Escobar José; OLIVEIRA, Luiz Eduardo. A Reforma Capanema e a Hegemonia do Ensino de Literatura. Revista HELB. Brasília, $\mathrm{n}^{\circ} 4$.

Crítico questiona Literatura Brasileira (2001). Estadão.com.br: Caderno $2 . \quad$ Disponível em <http://www.estadao.com.br/arquivo/arteelazer/2001/not20010203p3 286.htm>. Acesso em 28 de maio de 2013.

OLIVEIRA, Luiz Eduardo. "A (Re)Construção da Nação e a Formação de Líderes: o Ensino de Literatura no Estado Novo". In: CONGRESSO INTERNACIONAL DA ABRALIC, XI, 2008, São Paulo. Anais do XI Congresso Internacional da ABRALIC: Tessituras, Interações, Convergências. São Paulo: ABRALIC/USP, 2008.

Recebido em 04/02/2016. Aprovado em 02/04/2016.

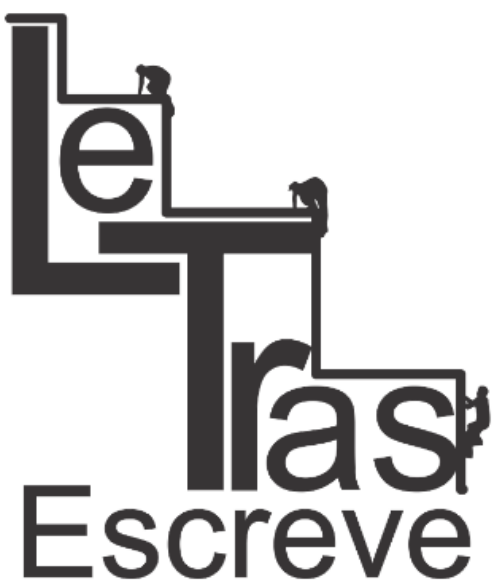

(ISSN 2238-8060) 